These plants are relatively plastic, and were able to make the necessary adjustments as the pond became a swamp, and the swamp passed through its various stages until it became a tillable field. In many of our farming regions, where this work of reclaiming was carried on almost entirely by these natural processes, a number of these readapted plants are to be found. The changes in the environment took place sufficiently slowly to make adaptations possible. In many other places artificial drainage and artificial removal of existing plant societies have made the changes in the environment so abrupt that plants could not make the adaptations necessary for growth in these new conditions, and there is little remaining besides the structure and contour of the land to suggest the former conditions.

\title{
Principles of Correlation
}

\section{Francis W. Parker}

I. A fundamental error in education is the isolation of subjects on the lines of conventional classification, thus attempting to separate, by teaching, the thought of one particular subject from the thought of other subjects to which it is organically related.

The educative value of one subject is primarily determined by its organic relations to all other subjects. It is therefore impossible to appreciate, or even to understand, any subject without knowing that it is but a part of the whole, and that each part penetrates the whole. Each subject has definite relations to all subjects; thus Physics and Chemistry are the sciences of ever-changing matter, and therefore intrinsic to the study of all other subjects. The distribution of heat, air, moisture, plant and animal life, over the earth's surface, cannot be profitably studied without a knowledge of the earth's surface.

II. Unity of Subjects: I. Man and Nature comprebend all subjects. These two are one in the Creator and the created. The essence of the knowledge of Man and Nature is law; and law has its function in life. Life, then, is the central subject of study.
III. Examination of Correlated Subjects: InORGanic Matter. Physiography presents the knowledge of the earth's structure and surface.

Geology is the history of the continual changes in the earth's rock envelope or crust. Geology, then, is the history of Physiography: Physiography presents the effects and Geology the causes.

Mineralogy presents the knowledge of the nature and composition of the rock crust or of the material which is constantly undergoing geological and physiographical changes.

Unity: The present surface (Physiography), the changing surface (Geology), the material which changes (Mineralogy).

Meteorology teaches the action of heat, moisture, and air upon and in the earth's crust; and their distribution over the earth's surface. Heat, moisture, air, are the causes of changes in the rock crust (Geology), in the surface of the earth (Physiography), and in the composition of rock material (Mineralogy).

Unity: Causes of changes in the earth's crust (Meteorology), the changes (Geology), the intrinsic effects of changes (Mineralogy), the surface effects of changes (Physiography). 
Three Earth Envelopes: I. Rock, solid and pulverized. 2. Water. 3. Atmosphere.

These three envelopes, which interpenetrate each other, are constantly changing under laws. Physics and Chemistry present the causes, and therefore the laws, of all changes in inorganic matter. It follows that intrinsic knowledge of all inorganic matter depends upon a knowledge of Physics and Chemistry.

Unity: Changes in the earth's crust (Geology), in the nature and composition of rock (Mineralogy), in the resultant changes in surface (Physiography), in causes of changes (Meteorology); which in turn depend absolutely upon the laws of Physics and Chemistry. For instance, the movements of the earth's crust may be comprised under (I) volcanic action (Physics and Chemistry), (2) folding and faulting (Physics), (3) erosion (Physics), (4) building with eroded material by running water and winds (Physics). For instance: Changes in composition of rock by heat and moisture (Physics and Chemistry); changes in kinds of rock (Physics and Chemistry); changes in the earth's surface (Chemistry and Physics); in moisture and air (Physics).

IV. Correlation may be illustrated by distribution.

One outcome of the study of physiography is a knowledge of the distribution and relation of the surface forms of the earth-mountain ranges, river basins, plains, plateaus, etc. A knowledge of this distribution involves a knowledge of the architecture of continental and island structure (Geology), and the material out of which they are constructed (Mineralogy).

I. A working knowledge of Physiography makes a knowledge of the distribution of heat (Mathematical Geography) possible.

2. A knowledge of surface forms and the distribution of heat is the basis of a knowledge of air distribution.
3. Heat and air distribution explains moisture distribution.

4. Upon a knowledge of surface forms and soils (Mineralogy), and the distribution of heat and moisture (Meteorology), depends the knowledge of the distribution of plants.

5. Upon all the foregoing facts $(I, 2,3,4)$ depends the distribution of animal life, including man.

Note.-Elementary study has for its purpose a preparation for the study of distribution. This probably may be accomplished in the Eighth or Ninth Grade. Correlation is absolutely essential to profitable elementary study.

V. The Function of Inorganic Matter is Life: I. Plant Life. Plants depend upon (a) a surface environment (Physiography); (b) soil (Mineralogy); (c) heat (Physics); (d) air (Meteorology); (e) drainage-movement of water in the soil and on the surface (Physics and Chemistry); (f) fertilizing-changes in soil (Chemistry).

Note.-A knowledge of any plant comprehends its physiographical, vegetable and animal environment, climate, soil, the nourishment of the plant by moisture, the function of its water table (Geology), capillary attraction (Physics), evaporation and transpiration.

2. Animal Life. A knowledge of animal life comprehends a knowledge of inorganic plant matter under all its classifications, and a knowledge of plant life and its relation to other animals, including man.

3. Man's Life. Nature furnishes man with food, clothing, shelter, luxuries, means of communication and transportation, etc.

The key to man's evolution is his physical environment (surface forms, climate, soil, animal life), and his relations to the rest of mankind. Life on the plains, in woods and mountains, the surrounding plants and animals, enter into and become strong factors in individual and community life. All the sciences of man have the closest relations to naturearchæology, philology, anthropology, and ethnology. The philosophy of history can be understood only by the closest study of man's environment. Literature is the study of man and nature. Arts and crafts are the expressions of man under the influences of nature and society.

VI. The Principles of Study: I. How to study is a question of immense, if not the greatest, importance in education. Man and nature are the sources of knowledge. They 
comprehend, therefore, the subjects of all study.

2. Attention to educative subjects is study. Attention is the holding in mind of images for their growth.

3. A strong image is (a) a close correspondence to an external object, (b) a unit consisting of strong. related images.

4. Analysis, judgment, inference, and reason have images for their intrinsic basis. A philosophical memory is possible only under the potency of strong images. The function of language is to hold and unite images, and the results of image growth.

5. There are three modes of attention defined by external stimuli: Observation, hearinglanguage, and reading.

6. Observation is imaging under the stimulus of an external object acting upon consciousness; the purpose of observation should be the formation of a strong image corresponding to the object observed.

7. Hearing-language and reading have both the same function, to wit: the union of images that have been previously in consciousness.

These processes become study when the images are held in consciousness for growth.

The laws for the concentration and expansion of images are complied with when correlated images come freely into consciousness, unobstructed by the limits of one class of objects or subjects. Following a single classification means the exclusion of images that should make the central image strong. For instance, the images of history, excluding physiography, meteorology, botany, etc., are in a marked degree weak or attenuated. Physics and chemistry, without the images of the materials changed under the action of physical and chemical forces, induce an obscurity of image.

Conclusion: From the standpoint of external objects and from that of psychology, the isolated teaching of subjects is absolutely unpedagogical.

Discipline and skill in all the modes of attention are best acquired through the energy of growing, correlated images.

All educative acts of attention should be the imaging of Man and Nature; that is, all study should be concentrated upon these subjects. Thoroughness in knowledge consists of strong, correlated images. The processes of attention should be acquired under the energy of imaging.

Expression in all its modes-gesture, speech, music, making, modeling, painting, drawing, writing - has three influences upon human growth: (a) Physical development in making the body, including its agents, effectively responsive to the will; (b) mental development in the reaction of molor discharge upon consciousness; (c) strengthening and disciplining moral growth under a high ideal.

The best physical growth is the best mental and moral development. Each mode of expression has its special reactive and educative function, for which no one or all of the other modes can be substituted.

Elementary skill in all the modes of expression may be best and most economically acquired through the manifestation of educative thought. The eight years of the elementary school may be spent in the direct study of Man and Nature, which means that both attention and expression should be concentrated upon the study of nutritive subjects.

Under the purpose of acquiring certain definite quantities of knowledge the attempt to teach in the most elementary way all the subjects classified under Man and Nature, together with the development of power and skill in all the modes of attention and expression, would be fatal in the extreme; it would be attempting the impossible. Under the ideal of knowledge-getting there is no guide to the selection and adaptation of knowledge.

VII. The End and Aim of Education: I. An ideal determines everything that goes into its realization: knowledge, reason, discipline, interest, and method. 
Note. - The ideal meant is the personal one held by the pupil.

2. The greater the ideal the more useful it is to humanity; the more knowledge, reason, discipline, interest, it demands for realization.

3. The needs of society determine the work of the school. Put that into the school which society should have for its improvement.

4. The predominant need of society is character expressed in terms of citizenship.

5. The end and aim of citizenship is ideal community life.

6. The school should be an organization of ideal community life, in which every pupil is a citizen, or is becoming one.

7. The teacher is the organizer of the best society, and the creator of a healthy, normal, moral public opinion.

8. The nature and capacity of the pupil determine his personal relationship to the community (school) of which he is a member. Citizenship develops the best, all the best, and only the best in the child.

9. Knowledge is absolutely essential to the development of the citizen and the progress of the community.

IO. The highest and most persistent incentive to learning, under the direction of an efficient organizer of society, is the desire to help others.

II. Every ideal determines the knowledge needed to realize it. The knowledge necessary to realize community life is the broadest, deepest, most comprehensive.

12. In all the practical work of life, correlation is always the common sense rule. Uncorrelated knowledge is not usable.

VIII. Course of Study: I. 'The needs of a growing community life (school grades) is the only proper guide to the selection of subjects of knowledge and skill for the course of study.

2. The spirit of helpfulness is the only righteous incentive to all school work.

3. Ideal community life is always growing in reality and growing in outlook; therefore a true course of study is constantly changing in its adaptation to changing needs and growing ideal.

4. Under this ideal, expression in all its modes is using knowledge for the good of others. Study is preparation for use. Moral power is acquired by using knowledge for the best good of the community.

IX. Concentration: I. Under the ideal of citizenship and community life, concentration may be defined as bringing to bear the whole beingpersonality, originality, research, reason-upon the realization of complete living in the school.

2. Concentration may be enhanced a thousand-fold by unity of purpose on the part of an entire faculty.

3. The study of the needs of community life is infinite in its possibilities. Under self-government, the ideal of society is growth. Anything fixed in method or system is impossible.

4. This ideal demands the closest study of the nature and possibilities of the child.

5. Each child becomes a member of society, a factor in civilization; he is led slowly and steadily to feel and understand his responsibilities as a citizen.

6. Concentration demands correlation. The question of questions is, what is the best knowledge to community life? - thus breaking down the unpedagogical barriers of classification.

7. Concentration is the economy of physical, mental, and moral action. The reason why students in general know so little is that knowledge, and not character, is made the end of education.

\section{Notes on Psychology}

\section{Nettie A. Sawyer}

(Fall Quarter)

Statement: "I see" means I am conscious of an image.

Experiment: I experiment with books, hats, pencils, lamps, etc. Only when 1 am conscious of an image do I see a thing.

Question: Is there a state of consciousness without an image?

Experiment: I recall to memory a face, a saying, an act, a landscape-in every case I have an image-in the case of the saying, there may be more or less images according to circumstances. When I recall some quotation from a poem I simply image the contents of the extract, as in "The day is cold, and dark, and dreary."

When I reason I have images.

Example: I say: "All quadrupeds are fourfooted. This animal has four feet, therefore it is a quadruped." Here I have vivid images in both parts. I experiment again with reasoning. I say: "This man has died; that man died. All men I have known have been under a certain age; therefore all men must die." I have images, though different from the above. 